\title{
The Effect of Chronic Usage of Renin-Angiotensin- Aldosterone System Blocking Agents on Incidence of Contrast-Induced Nephropathy in Patients with Diabetes Mellitus and Renal Insufficiency. a Retrospective Cohort Study.
}

\author{
Astika Widy Utomo', Dwi Aris Agung Nugrahaningsih2, Iwan Dwiprahasto2,
}

\begin{abstract}
Background: This study was to investigate the effect of long term use of Renin-Angiotensin-Aldosterone System (RAAS) blocking agents on the Incidence of Contrast-Induced Nephropathy (CIN) on patients with Diabetes Mellitus (DM) and renal insufficiency underwent Percutaneous Coronary Intervention ( $\mathrm{PCl})$.

Methods: A total 28I of subjects were included in this study and divided into two groups based on prior use of RAAS blocking agents (RAAS +, $n=146$; RAAS -, $n=135$ ). CIN was defined as an increase of $\geq 25 \%$ in creatinin over baseline value 48-72 hours after $\mathrm{PCl}$.

Results: Total incidence of CIN was I4,95\%. There was no difference in the incidence of CIN between 2 study groups ( $p$ $=0,952)$ and relative risk for CIN was I,02. Left Ventricular ejection Fraction (LVEF) $\leq 40 \%$ (OR 2,300; 95\% Cl I,028 $-5, I 43 ; p=0,043)$, anemia (OR 2,628; $95 \% \mathrm{Cl} \mathrm{I,274-5,422;} \mathrm{p}=0,009$ ) and Glomerular Filtration rate (GFR) pre PCl $\leq 60 \mathrm{~mL} /$ minute (OR 2,782; 95\% Cl I,293 - 5,987; $\mathrm{p}=0,009)$ were important predictors of CIN.

Conclusion: Long term use of RAAS blocking agents do not increase the incidence of CIN in patients with DM and renal insufficiency underwent $\mathrm{PCl}$.
\end{abstract}

(Indonesian J Cardiol. 2019;40:195-20I)

Keywords: DM, CIN, PCI, RAAS blocking agents, renal insufficiency

IDepartment of Pharmacology and Therapy, Faculty of

Medicine, Diponegoro University, Indonesia

2 Department of Pharmacology and Therapy, Faculty of

Medicine, Universitas Gadjah Mada, Indonesia

Correspondence:

Astika Widy Utomo, MD, M.Sc

Department of Pharmacology and Therapy,

Faculty of Medicine, Diponegoro University,

E-mail: astikautomo@gmail.com

\section{Introduction}

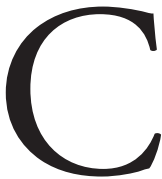

ontrast-Induced Nephropathy (CIN) is one of a serious complication of Percutaneous Coronary Intervention (PCI) whose incidence varies from $2 \%-25 \%$ based on population and risk factors 1,2 . CIN is usually defined as an increase in serum creatinine by $25 \%$ or by $0,5 \mathrm{mg} /$ $\mathrm{dL}(44 \mathrm{mmol} / \mathrm{L})$ from a baseline value by $48-72$ hours post-contrast administration3. Renal insufficiency, diabetes mellitus $(\mathrm{DM})$, congestive heart failure $(\mathrm{CHF})$, 
Tabel 1. Baseline characteristics

\begin{tabular}{lccc}
\hline \multicolumn{1}{c}{ Characteristics } & RAAS $+(146)$ & RAAS $-(135)$ & p-value \\
\hline Age, years & $60,91 \pm 8,27$ & $58,71 \pm 11,48$ & 0,069 \\
BMI & $24,66 \pm 3,47$ & $24,59 \pm 2,99$ & 0,620 \\
SBP & $139,30 \pm 26,84$ & $137,73 \pm 26,40$ & 0,155 \\
DBP & $80,47 \pm 18,18$ & $83,51 \pm 17,57$ & 0,080 \\
Hemoglobin & $13,32 \pm 1,77$ & $13,70 \pm 1,92$ & 0,344 \\
Cholesterol & $169,86 \pm 47,87$ & $175,29 \pm 48,03$ & 0,116 \\
LVEF & $46,69 \pm 16,66$ & $43,67 \pm 15,46$ & 0,053 \\
Duration of PCI & $66,42 \pm 25,57$ & $60,82 \pm 22,71$ & 0,169 \\
Contrast amount & $165,19 \pm 72,62$ & $154,41 \pm 56,97$ & 0,065 \\
Mehran score & $10,29 \pm 3,64$ & $9,49 \pm 3,64$ & 0,679 \\
CHF & $51(34,9 \%)$ & $44(32,6 \%)$ & 0,763 \\
Female gender & $28(19,2 \%)$ & $24(17,8 \%)$ & 0,976 \\
NAC & $37(25,3 \%)$ & $34(25,2 \%)$ & 0,284 \\
Hypertension & $27(18,5 \%)$ & $32(23,7 \%)$ & $2(1,5 \%)$ \\
Hypotension & $3(2,1 \%)$ & $39(38,9 \%)$ & 0,537 \\
Hypercholesterolemia & $33(22,6 \%)$ & $46(34,1 \%)$ & 0,228 \\
Anemia & $55(37,7 \%)$ & & 0,530 \\
\hline
\end{tabular}

dehydration, elderly, anemia, and nephrotoxic drugs such as nonsteroidal anti-inflammatory drugs (NSAID) are known risk factors for CIN4. The development of CIN has been associated with increased length of hospitalization and 3x incidence of MACCE (Major Adverse Cardiac and Cerebrovascular Events) at 1 year follow up ie: death, stroke, myocardial infarction (MI), and end-stage renal disease 5 .

The role of the Renin-Angiotensin-Aldosterone System (RAAS) blocking agents in CIN is still controversial. Data from available literature are conflicting and discordant. Some study concluded that it was effective in the prevention of $\mathrm{CIN}^{2,6}$, but other studies concluded that it was a risk factor $1{ }^{7-9}$. The reason behind these conflicting results is the pathomechanism of CIN that remain unclear. There is two main mechanisms leading to CIN, renal vasoconstriction induced medullary hypoxia, and direct toxicity of contrast media ${ }^{10}$. It has been speculated that RAAS blocking agents may decrease the vascular tone of efferent arteriole used to maintain glomerular hydrostatic pressure. The lower the hydrostatic pressure, the less glomerular filtration $1^{1,12}$. Experimental data suggest that increased endothelin-1, and reactive oxygen species are vital in the development of CIN, and can be inhibited using RAAS blocking agents ${ }^{13}$.

\section{Methods}

\section{Study Population}

An observational study with historical cohort design using medical records was performed in patients who were referred to National Cardiac Center "Harapan Kita" Hospital Jakarta for non-emergent PCI between January 2012 and December 2013. Inclusion criteria were age > 18 years old, diagnosed with DM and renal insufficiency (GFR $30-89 \mathrm{~mL} / \mathrm{min}$ ) at least 3 months prior to PCI, and Mehran score $>5^{14}$. Patients were excluded if they had the following criteria: prior condition leading to renal hypoperfusion (i.e hypovolemia, systolic pressure $<90 \mathrm{mmHg}$, cardiogenic shock, cardiac arrest, sepsis, obstructive uropathy), administration of contrast load within 7 days, severe renal impairment (GFR $<30 \mathrm{~mL} /$ min), subsequent surgery following PCI, nephrotoxic agent administration within 48 hours before the procedure (NSAIDs, amphotericin B, aminoglycosides, cyclosporine), and severe anemia require blood transfusion. All patients received normal saline at rate $1 \mathrm{~mL} / \mathrm{kg} / \mathrm{h} \sim$ maximum $100 \mathrm{~mL} / \mathrm{h}$ for $6 \mathrm{~h}$ before and 6 $\mathrm{h}$ after PCI. A total of 281 subjects met the inclusion criteria and divided into two groups: the RAAS (+) group $(\mathrm{n}=146)$, who received any type of RAAS 
Indonesian Journal of Cardiology

Table 2. Post PCI changes in renal parameters in two study groups

\begin{tabular}{lcccc}
\hline & RAAS + & RAAS & $95 \%$ CI & p-value \\
\hline GFR (mL/min) & & & & \\
Baseline & $49,85 \pm 14,34^{\mathrm{a}}$ & $51,92 \pm 14,46^{\mathrm{b}}$ & $-2,07(-5,46-1,31)$ & 0,229 \\
Post PCI & $51,28 \pm 18,57^{\mathrm{a}}$ & $56,52 \pm 20,78^{\mathrm{b}}$ & $-5,23(-9,86-0,62)$ & 0,026 \\
Absolute change & $1,43 \pm 13,71$ & $4,60 \pm 19,50$ & $-3,17(-7,10-0,77)$ & 0,114 \\
sCr (mg/dL) & & & & \\
Baseline & $1,49 \pm 0,42^{\mathrm{c}}$ & $1,45 \pm 0,42^{\mathrm{d}}$ & $0,04(-0,06-0,14)$ & 0,429 \\
Post PCI & $1,52 \pm 0,58^{\mathrm{c}}$ & $1,45 \pm 0,66^{\mathrm{d}}$ & $0,07(-0,08-0,22)$ & 0,345 \\
Absolute change & $0,03 \pm 0,47$ & $-0,003 \pm 0,58$ & $0,03(-0,09-0,156)$ & 0,626 \\
\hline
\end{tabular}

Values are means \pm SD

Student's $\mathrm{t}$ test was used in statistical analysis between the groups and paired t-test in subject comparison. ${ }^{\mathrm{a}} \mathrm{p} 0,210 ;{ }^{\mathrm{b}} \mathrm{p} 0,007$; ${ }^{c}$ p 0,$471 ;{ }^{d}$ p 0,954

blocking agents at least 3 months before admission, and the RAAS (-) group ( $\mathrm{n}=135)$, who did not received any RAAS blocking agents before admission.

\section{Study Variables and Definitions}

CIN was defined as an increase of $\geq 25 \%$ or $\geq 0,5 \mathrm{mg} / \mathrm{dL}$ $(\geq 44 \mathrm{mmol} / \mathrm{L})$ in serum creatinine over the baseline value within $48-72 \mathrm{~h}$ of $\mathrm{PC}^{\mathrm{l}}$. DM was defined as a fasting plasma glucose $\geq 126 \mathrm{mg} / \mathrm{dL}$, and or an oral glucose tolerance test $\geq 200 \mathrm{mg} / \mathrm{dL}$, and or an AIC $\geq 6,5 \%$, and or clinical diagnosis of diabetes with dietary, oral or insulin treatment ${ }^{15}$. GFR was calculated using Cockroft Gault: $(140$ - age $)$ x weight $(\mathrm{kg}) /$ serum creatinine $(\mathrm{mg} /$ dL) $x 72$ ( 0,8 in female). Patients with blood pressure $\geq 140 / 90 \mathrm{mmHg}$ were regarded as having hypertension. The presence of anemia was defined as a hemoglobin concentration $<12,0 \mathrm{~g} / \mathrm{dL}$ in female or $<13,0 \mathrm{~g} / \mathrm{dL}$ in male. Hypercholesterolemia was defined as having a total cholesterol concentration $>200 \mathrm{mg} / \mathrm{dL}$. LVEF $\leq 40 \%$ was examined using echocardiography before PCI. CHF was defined as NYHA III-IV criteria with LVEF $\leq 40 \%$. Mehran score was calculated according to the assessment of the associated risk factors, including volume of contrast media, baseline GFR, age, presence of hypotension, $\mathrm{CHF}$, presence of anemia, and diabetes mellitus. A cutoff value of $60 \mathrm{~mL} / \mathrm{min}-89 \mathrm{~mL} / \mathrm{min}$ and $30 \mathrm{~mL} / \mathrm{min}-59 \mathrm{~mL} / \mathrm{min}$ in GFR were used to define mild and moderate renal insufficiency, respectively ${ }^{3}$.

\section{Statistical Analysis}

Continuous variables were given as mean \pm standard deviation, and the comparisons of these variables were performed using student's t-test. Within-subjects comparisons of continuous variables i.e GFR and $s \mathrm{Cr}$ were completed using the paired t-test. Categorical variables were analyzed using chi-square and were presented as absolute value and percentage. We performed bivariate analysis with $\mathrm{CIN}$ as dependent variables and potential risk factors as follow: age, BMI, LVEF, duration of PCI was performed, contrast amount, Mehran score, variance of contrast media, use of RAAS blocking agent, hypertension, anemia, hypercholesterolemia, gender, CHF, use of NAC, GFR, and $\mathrm{sCr}$. Variables that were statistically significant in bivariate analysis were included in the final multivariate model to identify predictors of CIN. P-value $\leq 0,05$ was considered for statistical significance. A $2 \times 2$ table was used to calculate the relative risk of CIN. We performed statistical analysis using statistical analysis software.

\section{Results}

Two hundred and eighty-one (281) subject were included in the final analysis. Baseline characteristic is shown in table 1 .

\section{Markers of renal functions and incidence of CIN}

Mean GFR before PCI was $50,85 \mathrm{~mL} / \mathrm{min}$ with range $30,05-89,27 \mathrm{~mL} / \mathrm{min}$. Mean sCr before PCI was 1,47 $\mathrm{md} / \mathrm{dL}$ with $0,7 \mathrm{mg} / \mathrm{dL}$ as minimum value and $3,0 \mathrm{mg} /$ $\mathrm{dL}$ as maximum value. Before PCI the two groups had comparable renal markers (table 2). After PCI, RAAS (-) groups had significantly higher GFR compare to RAAS $(+)(\mathrm{p}=0,026)$, as shown on absolute change ( $\mathrm{p}$ $=0,007)$. 
Table 3. Predictors CIN

\begin{tabular}{lccc}
\hline \multicolumn{1}{c}{ Predictors } & OR & $95 \%$ CI & P-value \\
\hline LVEF $\leq 40 \%$ & 2,300 & $1,028-5,143$ & 0,043 \\
Duration of PCI was performed & 1,955 & $0,965-3,958$ & 0,063 \\
$>65$ minutes & & & \\
Anemia & 2,628 & $1,274-5,422$ & 0,009 \\
CHF & 1,567 & $0,697-3,524$ & 0,277 \\
GFR $\leq 60 \mathrm{~mL} / \mathrm{min}$ & 2,782 & $1,293-5,987$ & 0,009 \\
\hline
\end{tabular}

CIN occurred in $14,95 \%$ (42 of 281) of overall study population, 22 patients $(15,07 \%)$ on RAAS $(+)$ group, and 20 patients $(14,82 \%)$ on RAAS (-) group. There was no statistically significant difference in the incidence of CIN between two study groups (p 0,952). The relative risk of CIN based on chronic usage of RAAS blocking agents was 1,02 .

\section{Bivariate and Multivariate Analysis}

On bivarate analysis, we studied 16 risk factors for the development of CIN. From the analysis, we found 5 risk factors were associated with CIN were LVEF $\leq$ $40 \%$ (OR 2,421; 95\% CI 1,233-4,751; p = 0,009), duration of PCI was performed > $65 \mathrm{~min}(\mathrm{OR} 2,021$; 95\% CI 1,041 - 3,952; p = 0,035), anemia (OR 1,988; 95\% CI $1,025-3,852 ; \mathrm{p}=0,040)$, CHF (OR 1,988; 95\% CI 1,023 - 3,863; p = 0,040), and GFR pre $\mathrm{PCI} \leq 60 \mathrm{~mL} / \mathrm{min}(\mathrm{OR} 2,683$; CI 1,312 - 5,485; $\mathrm{p}=0,005)$. Multivariate analysis showed that LVEF $\leq$ $40 \%$, anemia, and GFR pre PCI $\leq 60 \mathrm{~mL} / \mathrm{min}$ were important predictors of CIN (Table 3 ).

\section{Discussion}

\section{RAAS blocking agents usage and CIN}

In this study, we found that there is no difference in CIN incidence in subjects with DM and renal insufficiency who were under chronic use of RAAS blocking agents or not. This result was clinically important since previous studies gave inconsistent results ${ }^{1,6,8,9,16}$. CIN was one of the important complications after contrast administration for medical intervention and associated with an increased hospital stay and cost ${ }^{17}$.

Mean Mehran score in this study was 9,52 $\pm 3,73$. This meant that we had a chance to develop CIN as
$14 \%{ }^{14}$. This exactly predicted a $14,95 \% \mathrm{CIN}$ incidence in our total study population. Our finding was significantly lower than the previous study in the same center. On the previous study, the incidence of CIN was up to $25 \%$. The reason probably was the difference between our study population, and prevention procedure that was a must in our study design ${ }^{18}$. Some study stated that prevention procedure decreases CIN significantly 9

One reason to explain these different results is the complex mechanism of CIN. Medullary hypoxia due to renal blood flow hypoperfusion secondary to arteriolar vasoconstriction dan direct toxicity of contrast media is widely known as the mechanism of $\mathrm{CIN}^{19}$. The imbalance between local vasoconstriction and local vasodilator also play a role in the development of CIN. Local vasoconstriction such as endothelin-1, renin, and angiotensin II compete with nitric oxide as a local vasodilator to maintain renal medullary perfusion. Increase the level of reactive oxygen species (ROS) and decrease the level of nitric oxide is also one mechanism leading to $\mathrm{CIN}^{12}$.

In our study, both groups experienced an increase in GFR level after PCI as a result of a progressive preventive procedure. Meanwhile, GFR after PCI was significantly lower in RAAS (+) than on RAAS (-), probably due to a hypothesis that angiotensin II-mediated post glomerular efferent arteriolar vasoconstriction is important to maintain renal to perfusion pressure. Chronic inhibition on angiotensin II will decrease intraglomerular pressure thus decrease $\mathrm{GFR}^{20}$. RAAS blocking agents on physiologic condition does not appear to have toxic properties, but these agents will cause serious renal insufficiency in a condition where angiotensin II is important to maintain GFR, i.e: bilateral stenosis of artery renal, severe dehydration, and hyponatremi ${ }^{7}$.

RAAS blocking agents are integral modalities for treatment of myocardial infarct, hypertension, heart failure. Many studies stated that these agents have 
beneficial effects on reducing the progression of renal failure in DM. Nevertheless, a systematic review from 5 RCTs with 678 patients concluded that there is no compelling evidence for stopping or starting ACE I before $\mathrm{PCI}^{21}$. The reasons behind this conclusion probably due to the heterogeneity of study designs, small sample size, the difference in a baseline population, prevention procedures, and different definition of CIN itself $^{21}$. In our study, we had younger subjects but with worse renal impairment. These pre-existing renal disease and medical conditions in both groups also helped to explain the result. The other factors were small sample size and wide individual variation. Although our finding did not answer the hypothesis, if we looked at a different view, chronic RAAS blocker usage did not have negative effects on younger subjects with renal impairment.

One thing not to forget is the chemical properties of RAAS blocking agents. Each of these agents has their own lipid solubilities, plasma protein bindings, bioavailabilities, plasma half-lives, and elimination properties which determine different onsets, duration of actions, and the effectivities of RAAS blockade. One to argue, these characteristics would lead to a different result on the development of CIN.

\section{Risk Factors of CIN}

$\mathrm{LVEF} \leq 40 \%$ is the main predictor of $\mathrm{CIN}^{22}$. Other studies suggested that LVEF $\leq 40 \%$ increased the likelihood of developing CIN $>7 \mathrm{x}^{23}$. Low LVEF are associated with poor hemodynamic and unstable perfusion to a target organ. The kidney is the target organ that suffers much when these conditions occurred since renal blood flow is affected by intrinsic and extrinsic factors. One to remember is pathomechanism of CIN that develop due to the decrease of renal blood flow following contrast administration ${ }^{19}$.

GFR $\leq 60 \mathrm{~mL} / \mathrm{min}$ is also an independent predictor for CIN and has an important predictive value ${ }^{24}$. GFR $\leq 60 \mathrm{~mL} / \mathrm{min}$ is clinically important since it's used as a cutoff value to define patients with renal impairment. Pre-existing renal impairment also an important risk factor for $\mathrm{CIN}^{14}$. Duration of PCI > $65 \mathrm{~min}$ also included in CIN predictors. Rationally, the longer the duration of PCI, the larger the amount of contrast media being used, and the longer the toxic effect of contrast media are exposed. The accumulation of these factors contributes to the development of $\mathrm{CIN}^{25,26}$. State of anemia prevalence to be found in patients with $\mathrm{DM}^{27}$. Studies stated that this condition was an important risk factor for $\mathrm{CIN}^{28,29}$. The outer medullary is prone to hypoxic condition due to high metabolic activities and low oxygen pressure. Contrast media increase the oxygen - hemoglobin affinity, therefore decreasing transfer oxygen to peripheral region ${ }^{28,29}$.

Our study has some limitations: the new definition of CIN was assigned in 2007 to accommodate a mild increase of serum creatinin that already had clinical implication ${ }^{30}$. Also in 2011, a new guideline stated that every patient prior to PCI need to perform a risk assessment and progressive prevention procedures. CIN decrease respectively with incidence $7,1 \%-9,6 \% 31,32$. However, we still used the old definition of CIN because of lack of data we had. This was a single-center study with historical cohort design, thus allowed bias on internal validity. On GFR, we still used Cockroft-Gault formulation to calculate renal function, although cystatin $\mathrm{C}, \mathrm{N}$-acetyl-glucosaminidase, and inulin clearance may provide a more sensitive estimate renal functions ${ }^{7}$. The heterogeneity duration after PCI to measure creatinine serum were also feared to cause inconsistencies in the study. However, this is the first study that discusses the relationship between chronic used of RAAS blocking agents especially in Indonesia and next study with the design that accommodates prospective or RCT are needed to examine the relationship lack in this study.

\section{Conclusion}

In conclusion, the present study state that chronic used of RAAS blocking agents do not increase the incidence of CIN. $\mathrm{LVEF} \leq 40 \%$, GFR $\leq 60 \mathrm{~mL} / \mathrm{min}$, and anemia are important predictors for CIN. A future study that accommodates a lack of finding in this study is needed.

\section{Ethical Clearance}

This study was approved by the ethic committee of National Cardiac Center "Harapan Kita" Hospital Jakarta no. LB.05.01.1.4/01/2015.

\section{Conflict Of Interest}

None 


\section{Publication Agreement}

The authors of this article give permission to Indonesian Journal of Cardiology to publish this article if this article is accepted

\section{Funding}

Self funded

\section{List of Abbreviations}

CHF: congestive heart failure

CIN: Contrast-Induced Nephropathy

DM: DIabetes Mellitus

GFR: Glomerular Filtration rate

LVEF: Left Ventricular ejection Fraction

NSAID: nonsteroidal anti-inflammatory drugs

PCI: Percutaneous Coronary Intervention

RAAS: Renin-Angiotensin-Aldosterone System

\section{References}

1. Umruddin Z, Moe K, Superdock K. ACE inhibitor or angiotensin II receptor blocker use is a risk factor for contrast-induced nephropathy. J Nephrol. 2012;25(5):776-81.

2. Spatz C, Saadulla L, Lapsiwala A, Parhizgar A, Ghahramani N. Effect of renin-angiotensinaldosterone system blockade therapy on incidence of contrast-induced nephropathy in patients with chronic kidney disease. Iran J Kidney Dis. 2012;6(6):432-6.

3. Uhlig K. Clinical Practice Guideline for Acute KidneyInjury In: Kidney International Supplements. Kidney Int[Internet]. 2012;2(1):i-iv; 1-138. https:// kdigo.org/wp-content/uploads/2016/10/KDIGO2012-AKI-Guideline-English.pdf

4. Evola S, Lunetta M, MacAione F, Fonte G, Milana $\mathrm{G}$, Corrado E, et al. Risk factors for contrast induced nephropathy: A study among italian patients. Indian Heart J [Internet]. 2012;64(5):484-91.

5. Solomon RJ, Mehran R, Natarajan MK, Doucet S, Katholi RE, Staniloae CS, et al. Contrast-induced nephropathy and long-term adverse events: Cause and effect? Clin J Am Soc Nephrol. 2009;4(7):11629 .

6. K Gupta R, Kapoor A, Tewari S, Sinha N, Sharma R. Captopril for prevention of contrast-induced nephropathy in diabetic patients: A randomised study. Vol. 51, Indian heart journal. 1998. 521-526 p.

7. Cirit M, Toprak O, Yesil M, Bayata S, Postaci N, Pupim L, et al. Angiotensin-converting enzyme inhibitors as a risk factor for contrast-induced nephropathy. Nephron Clin Pract [Internet]. 2006;104(1):c20-27. Available from: http://www. ncbi.nlm.nih.gov/pubmed/16685140

8. Baris N, Ozpelit E, Bilgin Dogan N, Kangul H, Gul S, Akdeniz B, et al. The effects of chronic usage of angiotensin-converting enzyme inhibitors and angiotensin receptor blockers on contrast-induced nephropathy in low-risk patients. Anadolu Kardiyol Dergisi/The Anatol J Cardiol [Internet]. 2012;24550. Available from: http://anatoljcardiol.com/jvi. aspx?un=AJC-67209

9. Hölscher B, Heitmeyer C, Fobker M, Breithardt G, Schaefer RM, Reinecke H. Predictors for contrast media-induced nephropathy and long-term survival: Prospectively assessed data from the randomized controlled Dialysis-Versus-Diuresis (DVD) trial. Can J Cardiol [Internet]. 2008;24(11):845-50.

10. Wong PCY, Li Z, Guo J, Zhang A. Pathophysiology of contrast-induced nephropathy. Int J Cardiol [Internet]. 2012;158(2):186-92.

11. Yacoub R, Patel N, Lohr JW, Rajagopalan S, Nader N, Arora P. Acute Kidney Injury and Death Associated With Renin Angiotensin System Blockade in Cardiothoracic Surgery: A Metaanalysis of Observational Studies. Am J Kidney Dis. 2013;62(6):1077-86.

12. Priestley JRC, Buelow MW, McEwen ST, Weinberg BD, Delaney M, Balus SF, et al. Reduced angiotensin II levels cause generalized vascular dysfunction via oxidant stress in hamster cheek pouch arterioles. Microvasc Res [Internet]. 2013;89:134-45.

13. Xiong $\mathrm{X}$ ling, Jia $\mathrm{R}$ han, Yang $\mathrm{D}$ ping, Ding $\mathrm{G}$ hua. Irbesartan attenuates contrast mediainduced NRK-52E cells apoptosis. Pharmacol Res. 2006;54(4):253-60.

14. Mehran R, Aymong ED, Nikolsky E, Lasic Z, Iakovou I, Fahy M, et al. A simple risk score for prediction of contrast-induced nephropathy after percutaneous coronary intervention: Development and initial validation. J Am Coll Cardiol. 2004;44(7):1393-9.

15. American Diabetes Association. Diagnosis and classification of diabetes mellitus. Diabetes Care. 
2010;33(SUPPL.1):62-69. https://www.ncbi.nlm. nih.gov/pmc/articles/PMC2797383/

16. Rosenstock JL, Bruno R, Kim JK, Lubarsky L, Schaller R, Panagopoulos G, et al. The effect of withdrawal of ACE inhibitors or angiotensin receptor blockers prior to coronary angiography on the incidence of contrast-induced nephropathy. Int Urol Nephrol. 2008;40(3):749-55.

17. Mccullough P a. Review CIN Consensus Working Panel : Am J Cardiol. 2008;4-10.

18. Yuniadi Y, Ningrum NR. Risk factors and incidence of contrast induced nephropathy following coronary intervention. 2008;17(2):131-7.

19. Rundback JH, Nahl D, Yoo V. Contrastinduced nephropathy. J Vasc Surg [Internet]. 2011;54(2):575-9.

20. Bainey KR, Rahim S, Etherington K, Rokoss ML, Natarajan MK, Velianou JL, et al. Effects of withdrawing vs continuing renin-angiotensin blockers on incidence of acute kidney injury in patients with renal insufficiency undergoing cardiac catheterization: Results from the Angiotensin Converting Enzyme Inhibitor/Angiotensin Receptor Bloc. Am Heart J [Internet]. 2015;170(1):110-6.

21. Patel K, King CA, Jovin IS. Angiotensin-converting enzyme inhibitors and their effects on contrastinduced nephropathy after cardiac catheterization or percutaneous coronary intervention. Cardiovasc revascularization Med Incl Mol Interv [Internet]. 2011;12(2):90-3. Available from: http://www.ncbi. nlm.nih.gov/pubmed/21421186

22. Chang CF, Lin CC. Current concepts of contrastinduced nephropathy: A brief review. J Chinese Med Assoc [Internet]. 2013;76(12):673-81.

23. Lucreziotti S, Centola M, Salerno-Uriarte D, Ponticelli G, Battezzati PM, Castini D, et al. Female gender and contrast-induced nephropathy in primary percutaneous intervention for ST-segment elevation myocardial infarction. Int J Cardiol [Internet]. 2014;174(1):37-42.

24. Robert AM, Brown JR, Sidhu MS, Ramanath VS, DeVries JT, Jayne JE, et al. The evaluation of creatinine clearance, estimated glomerular filtration rate and serum creatinine in predicting contrastinduced acute kidney injury among patients undergoing percutaneous coronary intervention. Cardiovasc Revascularization Med [Internet]. 2012;13(1):3-10.

25. Barbieri L, Verdoia M, Schaffer A, Marino P, De
Luca G. Contrast Volume To Creatinine Clearance Ratio in the Prediction of Contrast Induced Neprophathy in Patients Undergoing Coronary Angiography or Percutaneous Intervention. J Am Coll Cardiol [Internet]. 2015;65(10):A1747. Available from: http://linkinghub.elsevier.com/ retrieve/pii/S0735109715617478

26. Chen J, Liu Y. Contrast Volume To Creatinine Clearance Ratio Predicts Outcomes After Percutaneous Coronary Intervention. J Am Coll Cardiol [Internet]. 2012;59(13):E513. Available from: http://linkinghub.elsevier.com/retrieve/pii/ S0735109712605142

27. New JP, Aung T, Baker PG, Yongsheng G, Pylypczuk $\mathrm{R}$, Houghton J, et al. The high prevalence of unrecognized anaemia in patients with diabetes and chronic kidney disease: a population-based study. Diabet Med. 2008;25(5):564-9.

28. Murakami R, Kumita SI, Hayashi H, Sugizaki KI, Okazaki E, Kiriyama T, et al. Anemia and the risk of contrast-induced nephropathy in patients with renal insufficiency undergoing contrast-enhanced MDCT. Eur J Radiol [Internet]. 2013;82(10):e5214.

29. Shacham Y, Gal-Oz A, Leshem-Rubinow E, Arbel Y, Flint N, Keren G, et al. Association of admission hemoglobin levels and acute kidney injury among myocardial infarction patients treated with primary percutaneous intervention. Can J Cardiol [Internet]. 2015;31(1):50-5.

30. Mehta RL, Kellum JA, Shah S V., Molitoris BA, Ronco C, Warnock DG, et al. Acute kidney injury network: Report of an initiative to improve outcomes in acute kidney injury. Crit Care. 2007;11(2):1-8.

31. Tsai TT, Patel UD, Chang TI, Kennedy KF, Masoudi FA, Matheny ME, et al. Contemporary incidence, predictors, and outcomes of acute kidney injury in patients undergoing percutaneous coronary interventions: Insights from the NCDR cath-PCI registry. JACC Cardiovasc Interv. 2014;7(1):1-9.

32. James MT, Ghali WA, Knudtson ML, Ravani P, Tonelli M, Faris P, et al. Associations between acute kidney injury and cardiovascular and renal outcomes after coronary angiography. Circulation. 2011;123(4):409-16. 